\title{
Assessment of New Load Schedules for the Machine Calibration of a Force Balance
}

\author{
N. Ulbrich ${ }^{\dagger}$ \\ Jacobs Technology Inc., Moffett Field, California 94035 \\ R. Gisler \\ NASA Ames Research Center, Moffett Field, California 94035
}

\author{
R. Kew $\S$ \\ Triumph Aerospace, Force Measurement Systems, San Diego, California 92121
}

\begin{abstract}
New load schedules for the machine calibration of a six-component force balance are currently being developed and evaluated at the NASA Ames Balance Calibration Laboratory. One of the proposed load schedules is discussed in the paper. It has a total of 2082 points that are distributed across 16 load series. Several criteria were applied to define the load schedule. It was decided, for example, to specify the calibration load set in force balance format as this approach greatly simplifies the definition of the lower and upper bounds of the load schedule. In addition, all loads are assumed to be applied in a calibration machine by using the one-factor-at-a-time approach. At first, all single-component loads are applied in six load series. Then, three two-component load series are applied. They consist of the load pairs $(N 1, N 2),(S 1, S 2)$, and $(R M, A F)$. Afterwards, four three-component load series are applied. They consist of the combinations $(N 1, N 2, A F),(S 1, S 2, A F),(N 1, N 2, R M)$, and $(S 1, S 2, R M)$. In the next step, one four-component load series is applied. It is the load combination $(N 1, N 2, S 1, S 2)$. Finally, two five-component load series are applied. They are the load combination $(N 1, N 2, S 1, S 2, A F)$ and $(N 1, N 2, S 1, S 2, R M)$. The maximum difference between loads of two subsequent data points of the load schedule is limited to $33 \%$ of capacity. This constraint helps avoid unwanted load "jumps" in the load schedule that can have a negative impact on the performance of a calibration machine. Only loadings of the single- and two-component load series are loaded to $\mathbf{1 0 0} \%$ of capacity. This approach was selected because it keeps the total number of calibration points to a reasonable limit while still allowing for the application of some of the more complex load combinations. Data from two of NASA's force balances is used to illustrate important characteristics of the proposed 2082-point calibration load schedule.
\end{abstract}

\section{Nomenclature}

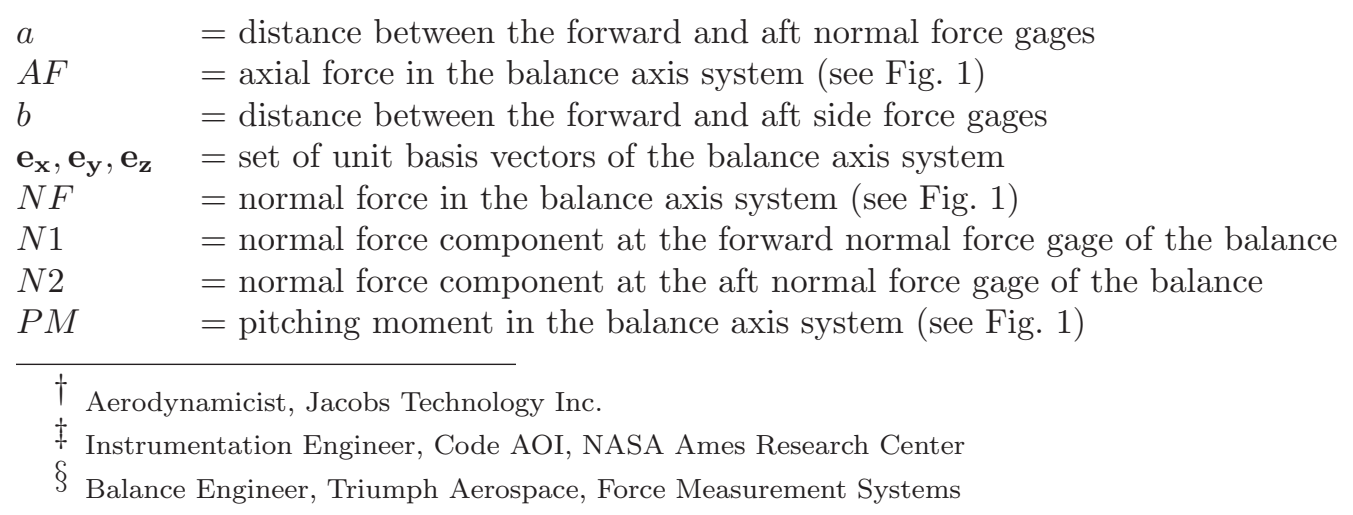




$\begin{array}{ll}R M & =\text { rolling moment in the balance axis system (see Fig. 1) } \\ S F & =\text { side force in the balance axis system (see Fig. 1) } \\ S 1 & =\text { side force component at the forward side force gage of the balance } \\ S 2 & =\text { side force component at the aft side force gage of the balance } \\ x & =\text { coordinate of the balance axis system that defines the direction of the axial force } \\ y & =\text { coordinate of the balance axis system that defines the direction of the side force } \\ Y M & =\text { yawing moment in the balance axis system (see Fig. 1) } \\ z & \text { = coordinate of the balance axis system that defines the direction of the normal force }\end{array}$

\section{Introduction}

New load schedules for the machine calibration of a six-component force balance are currently being developed and assessed at the NASA Ames Balance Calibration Laboratory in order to get a better understanding of the impact of load schedule design characteristics on the accuracy of balance load predictions. One of the proposed new load schedules is discussed in the paper. It has a total of 2082 data points, i.e., individual load combinations, that are distributed across 16 load series.

Past experience at the Ames Balance Calibration Laboratory and Triumph Aerospace showed that a load schedule for the calibration of a balance in a calibration machine is a compromise that has to take the potential use envelope of the balance during a wind tunnel test and constraints of the calibration machine itself into account. Several criteria were applied at the Ames Balance Calibration Laboratory during the design of the new machine calibration load schedules. They are discussed in the next section of the paper.

\section{Load Schedule Design Criteria}

Different criteria were applied at the Ames Balance Calibration Laboratory during the design of new load schedules for the machine calibration of a force balance. The calibration load schedule definition started with the selection of the load format. In theory, loads of a force balance may be defined in "force balance" format $(N 1, N 2, S 1, S 2, R M, A F)$ or in "direct-read" format $(N F, P M, S F, Y M, R M, A F)$. Figure 1 shows definitions in "direct-read" format (from Ref. [1]). Figures $2 \mathrm{a}$ and $2 \mathrm{~b}$ show the connection between loads in "direct-read" and "force balance" format (the load transformations are taken from Ref. [2]). The capacities of the load components in "force balance" format are a critical load schedule design parameter. They must not be exceeded. Therefore, after considering load transformations defined in Figs. 2a and 2b, the following inequalities must be satisfied when loads are applied in "direct-read" format to a force balance:

$$
\begin{aligned}
& |(N F / 2)+(P M / a)| \leq C A P A C I T Y(N 1) \\
& |(N F / 2)-(P M / a)| \leq C A P A C I T Y(N 2) \\
& |(S F / 2)+(Y M / b)| \leq C A P A C I T Y(S 1) \\
& |(S F / 2)-(Y M / b)| \leq C A P A C I T Y(S 2)
\end{aligned}
$$

Equations $(1 a)$ to $(1 d)$ above indicate that a "load limit test" in "direct-read" format is more complex than a corresponding test in "force balance" format. Applied loads in "direct-read" format have to be compared with corresponding capacities by using pairs of loads as input ( NF \& PM or SF \& YM). Loads in "force balance" format, on the other hand, are tested by comparing a single value with the load capacity ( $N 1$ or $N 2$ or $S 1$ or $S 2$ ). Therefore, it was decided to define the load schedule in "force balance" format as the load limit test is less complex. Consequently, a potential "accidental" overload of the balance can more easily be spotted in the load schedule design before the loadings are physically applied.

A balance calibration machine has the advantage that (i) a large number of loadings can be applied at minimum cost within a short period of time and that (ii) complex combined loadings can systematically be applied using the one-factor-at-a-time (OFAT) approach. Therefore, the OFAT approach was chosen for the new load schedule design. It makes the chosen load combinations immediately "apparent" to both an analyst and wind tunnel customer (see, e.g., the calibration load schedule given in Fig. 3).

Figure 3 shows all load combinations that were selected for the 2082-point calibration load schedule. The load schedule consists of 16 load series that were organized according to the load combination that

American Institute of Aeronautics and Astronautics 
was applied. The 16 load combinations themselves were selected by taking (i) anticipated aerodynamic loadings on the wind tunnel model and (ii) load prediction accuracy requirements during both performance and stability \& control tests into account.

Some loads or load combinations are needed for both performance and stability \& control tests. Other loads or load combinations are primarily needed for stability \& control tests, i.e., for tests of models at large sideslip and/or roll angles. In general, a customer's load prediction accuracy requirements are higher during performance tests, i.e., during tests when only the pitch angle of the model significantly differs from zero. Therefore, the "density" of calibration data points should be increased for loads or load combinations that are needed for both performance and stability \& control tests. Table 1 below summarizes loads and load combinations that are used in the proposed 2082-point calibration load schedule.

Table 1: Load and load combinations of the 2082-point load schedule for a force balance.

\begin{tabular}{|c|c|c|}
\hline $\begin{array}{c}\text { LOAD OR LOAD } \\
\text { COMBINATION } \\
\text { (BALANCE AXIS SYSTEM) }\end{array}$ & $\begin{array}{c}\text { EXPECTED PRIMARY } \\
\text { AERODYNAMIC LOADS } \\
\text { (WIND \& STABILITY AXIS SYSTEM) }\end{array}$ & $\begin{array}{l}\text { WIND TUNNEL TEST TYPE } \\
\text { P. } \equiv \text { performance test } \\
\text { S. \& C. } \equiv \text { stability \& control test }\end{array}$ \\
\hline$N 1$ & lift, drag, pitching moment & P. and S. \& C. \\
\hline$N 2$ & lift, drag, pitching moment & P. and S. \& C. \\
\hline$A F$ & lift, drag, pitching moment & P. and S. \& C. \\
\hline$N 1, N 2$ & lift, drag, pitching moment & P. and S. \& C. \\
\hline$N 1, N 2, A F$ & lift, drag, pitching moment & P. and S. \& C. \\
\hline$S 1$ & side force, yawing moment, rolling moment & S. \& C. \\
\hline$S 2$ & side force, yawing moment, rolling moment & S. \& C. \\
\hline$R M$ & rolling moment & S. \& C. \\
\hline$S 1, S 2$ & side force, yawing moment, rolling moment & S. \& C. \\
\hline$R M, A F$ & drag, rolling moment & S. \& C. \\
\hline$S 1, S 2, A F$ & $\begin{array}{l}\text { side force, drag, } \\
\text { yawing moment, rolling moment }\end{array}$ & S. \& C. \\
\hline$N 1, N 2, R M$ & $\begin{array}{l}\text { lift, drag, pitching moment, } \\
\text { rolling moment }\end{array}$ & S. \& C. \\
\hline$S 1, S 2, R M$ & $\begin{array}{l}\text { side force, yawing moment, } \\
\text { rolling moment }\end{array}$ & S. \& C. \\
\hline$N 1, N 2, S 1, S 2$ & $\begin{array}{l}\text { lift, drag, side force, pitching moment, } \\
\text { yawing moment, rolling moment }\end{array}$ & S. \& C. \\
\hline$N 1, N 2, S 1, S 2, A F$ & $\begin{array}{l}\text { lift, drag, side force, pitching moment, } \\
\text { yawing moment, rolling moment }\end{array}$ & S. \& C. \\
\hline$N 1, N 2, S 1, S 2, R M$ & $\begin{array}{l}\text { lift, drag, side force, pitching moment, } \\
\text { yawing moment, rolling moment }\end{array}$ & S. \& C. \\
\hline
\end{tabular}

At first, the principle single-component loads are applied in six load series (load series 1 to 6 ). Then, three two-component load series are applied (load series 7 to 9 ). They consist of the load pairs $(N 1, N 2)$, $(S 1, S 2)$, and $(R M, A F)$. Afterwards, four three-component load series are applied (load series 10 to 13). They consist of the combinations $(N 1, N 2, A F),(S 1, S 2, A F),(N 1, N 2, R M)$, and $(S 1, S 2, R M)$. In the next step, one four-component load series is applied (load series 14). It is the load combination $(N 1, N 2, S 1, S 2)$. Finally, two five-component load series are applied (load series 15 and 16). They are the load combination $(N 1, N 2, S 1, S 2, A F)$ and $(N 1, N 2, S 1, S 2, R M)$. 
Practical constraints were also considered during the design of the load schedule for the machine calibration of a force balance. For example, the maximum difference between loads of two subsequent data points of the load schedule was limited to $33 \%$ of capacity. This constraint helps avoid unwanted load "jumps" in the load schedule that can have a negative impact on the performance of a calibration machine. In addition, only loadings of the single- and two-component load series, i.e., loads of series 1 to 9 , are loaded to $100 \%$ of capacity. This approach was selected because it keeps the total number of calibration points to a reasonable limit while still allowing for the application of some of the more complex load combinations.

It is concluded, after comparing the contents of Fig. 3 with Table 1 above, that only load series 1, 2, 6 , 7, and 10 have a strong influence on the load prediction accuracy during performance tests of a wind tunnel model. These five load series consist of a total of 336 data points. The remaining 1746 data points, i.e., $84 \%$ of all data points of the proposed machine calibration load schedule, are needed to better characterize the balance performance during stability \& control tests. Therefore, the load schedule design and the total number of calibration points is driven by load prediction accuracy requirements of a stability \& control test.

Data of two force balances is used in the next section of the paper to illustrate important characteristics of the proposed 2082-point machine calibration load schedule.

\section{Examples}

First, data from NASA's MK26A balance is used to illustrate some basic features of the proposed 2082-point machine load schedule. The MK26A is a multi-piece balance that was manufactured by the Task Corporation. The balance is a six-component force balance that measures five forces and one moment (N1, N2, S1, S2, RM, AF). It has a diameter of 1.5 inches. Table 2 below shows the capacity of its load components.

Table 2: Load capacities of the MK26A balance.

\begin{tabular}{|c|c|c|c|c|c|}
\hline N1, lbs & N2, lbs & S1, lbs & S2, lbs & RM, in-lbs & AF, lbs \\
\hline 1000 & 1000 & 800 & 800 & 700 & 2000 \\
\hline
\end{tabular}

The balance was originally developed for the testing of spacecraft which explains its large axial force capacity. Load schedule design criteria listed in the previous section and in Fig. 3 were applied to generate a "hypothetical" machine calibration load schedule for the MK26A balance. Figure 4 shows all intended loads of the 2082-point load schedule for the MK26A plotted versus the data point index and load series number. It can clearly be seen that loads of the more complex combined loadings of load series 10 to 16 were not loaded to $100 \%$ capacity. This approach made it possible to keep the total number of calibration points to the reasonable limit of about 2000 .

A total of 15 combined load plots can be generated for a six-component force balance. These plots are a useful tool as they help better visualize the applied combined loadings in two-dimensional space. They can also be used to compare the "coverage" of the load envelope for different types of load schedule designs. Figures 5a, 5b, and 5c show all combined load plots for the chosen load schedule for the MK26A balance. It can clearly be seen that the four quadrants and associated quadrant boundaries are well captured for the three load combinations $(N 1, N 2),(S 1, S 2)$, and $(R M, A F)$. The "coverage" for the remaining 12 load combinations also appears to be good.

A 2034-point approximation of the proposed "hypothetical" 2082-point load schedule was applied to NASA's MC100A balance when it was first calibrated in Triumph Aerospace's Automatic Balance Calibration System $(A B C S)$. This experiment demonstrated that the proposed new machine calibration load schedule for force balances can be used in a "real-world" situation.

The MC100A is a six-component force balance that was manufactured by Triumph Aerospace in 2014. The balance measures five forces and one moment (N1, N2, S1, S2, RM, AF). It has a diameter of 2.5 inches. The MC100A balance was specifically designed for wind tunnel models that experience large rolling moments during a wind tunnel test. Table 3 shows the capacity of each load component. 
Table 3: Load capacities of the MC100A balance.

\begin{tabular}{|c|c|c|c|c|c|}
\hline $\mathrm{N} 1, \mathrm{lbs}$ & $\mathrm{N} 2, \mathrm{lbs}$ & $\mathrm{S} 1, \mathrm{lbs}$ & $\mathrm{S} 2, \mathrm{lbs}$ & $\mathrm{RM}$, in-lbs & AF, lbs \\
\hline 5000 & 5000 & 2500 & 2500 & 18000 & 800 \\
\hline
\end{tabular}

Figure 6 shows the calibration loads plotted versus the load series numbers that were applied in the $A B C S$ during the calibration of the MC100A balance. The 2034-point load schedule shows very good agreement with the "ideal" 2082-point load schedule that is depicted in Fig. 4 for the MK26A balance. This observation illustrates the fact that the proposed machine load schedule can be applied within the physical constraints of an existing balance calibration machine.

Figure 7a shows the load residuals of the fitted machine calibration data of the MC100A after a preliminary analysis of the data was completed. Comparing Fig. 6 with Fig. 7a it can be concluded that the larger-than-expected load residuals of the forward side force component $(S 1)$ of load series 12 appear to be linked to the application of the rolling moment $(R M)$ in combination with the forward and aft normal force components $(N 1, N 2)$. This example illustrates a key advantage of the new load schedule design: it makes connections between load residuals and applied load combinations more apparent. Therefore, it allows a wind tunnel customer to decide if some larger-than-expected calibration load residuals will have an impact on the loadings that the customer's model is expected to experience during a wind tunnel test.

Figure $7 \mathrm{~b}$ shows the preliminary calibration load residuals of the MC100A balance plotted versus the applied load. It can be seen that the proposed load schedule design for the machine calibration of a force balance concentrates more loadings near the origin of the coordinate system as the more complex load combinations are intentionally not applied to full capacity.

\section{Summary}

A new load schedule for the calibration of a six-component force balance in a balance calibration machine was developed at NASA Ames Research Center. The new load schedule consists of a total of sixteen load series with a total of 2082 data points that are applied using the OFAT approach.

Five of the sixteen load series support loadings that are experienced during both performance and stability \& control tests. The remaining eleven load series are primarily needed for stability \& control tests. Loads are applied to $100 \%$ capacity only for single- and two-component loadings. Series with three- or four-component loadings are loaded to a maximum of $66 \%$ of capacity. Series with five-component loadings are loaded to a maximum of $33 \%$ of capacity. This approach was selected in order to keep the total number of calibration points within a reasonable limit. In addition, the approach potentially helps avoid large superimposed stresses in a balance whose load paths are not well understood.

The proposed load schedule design for the machine calibration of a force balance has three major advantages. (1) Load series are clearly organized based on the type of wind tunnel test that the balance will be used for; this characteristic makes it easier for a wind tunnel customer to relate balance calibration data to the expected use envelope of the balance during a wind tunnel test. (2) Calibration load residuals can more easily be related to a specific load combination that was applied during the calibration; this feature makes the relationship between load combination type and residual magnitude more apparent which can be important for troubleshooting purposes. (3) More complex load combinations are primarily applied at lower load levels during the calibration; this approach increases the "density" of calibration points at lower load levels while keeping the total number of machine calibration points near the reasonable 2000-point limit.

Key elements of the proposed calibration load schedule design were applied to a force balance that was calibrated in Triumph's ABCS in 2014. A more detailed discussion of this calibration will be presented in a future conference paper.

\section{Acknowledgements}

The authors want to thank Tom Volden of Jacobs Technology for his critical and constructive review of the final manuscript of the paper. The work reported in this paper was partially supported by the Wind Tunnel Division at NASA Ames Research Center under contract NNA09DB39C. 


\section{References}

${ }^{1}$ American Institute of Aeronautics and Astronautics, Recommended Practice - Calibration and Use of Internal Strain Gage Balances with Application to Wind Tunnel Testing, AIAA R-091-2003, American Institute of Aeronautics and Astronautics, Reston, Virginia, 2003.

${ }^{2}$ Ulbrich, N., and Bader, J., "Analysis of Sting Balance Calibration Data Using Optimized Regression Models," AIAA 2009-5372, paper presented at the 45th AIAA/ASME/SAE/ASEE Joint Propulsion Conference, Denver, Colorado, August 2009, pp.18-21. 


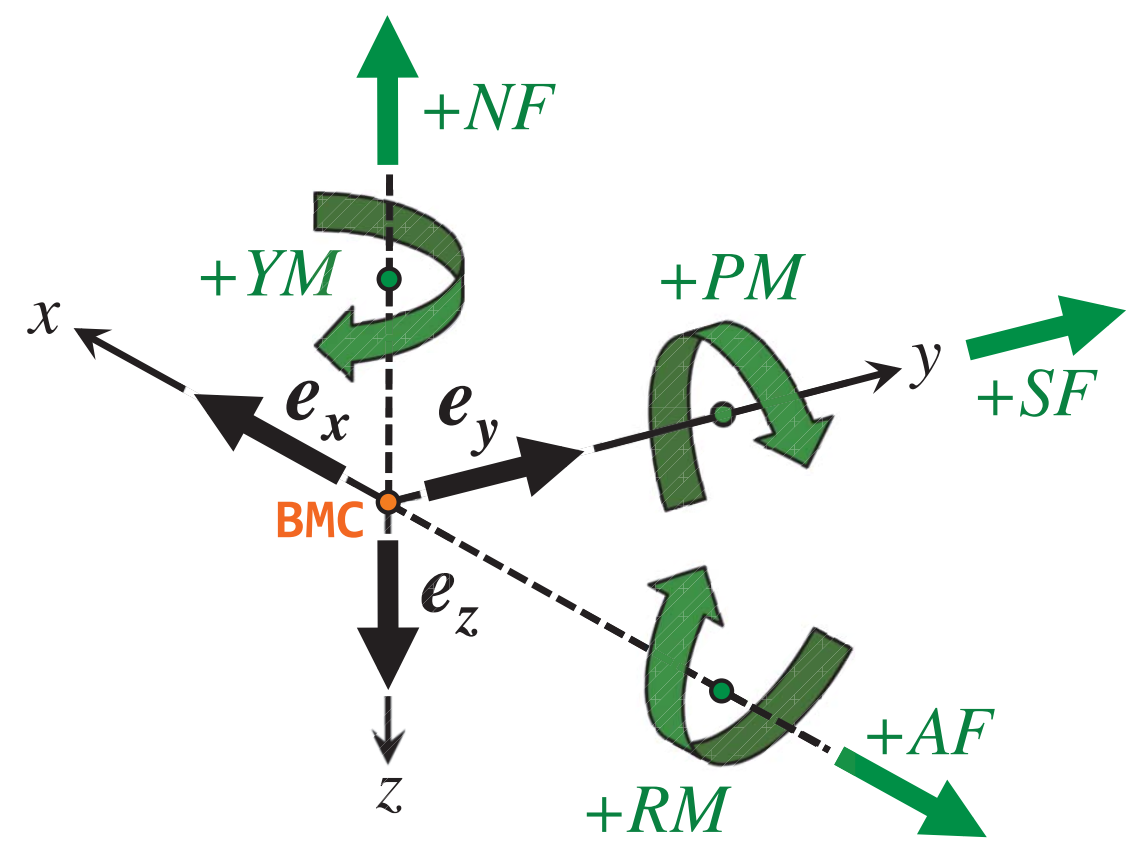

Fig. 1 Definition of Cartesian coordinates and load signs in the balance axis system (from Ref. [1], Fig. 1).

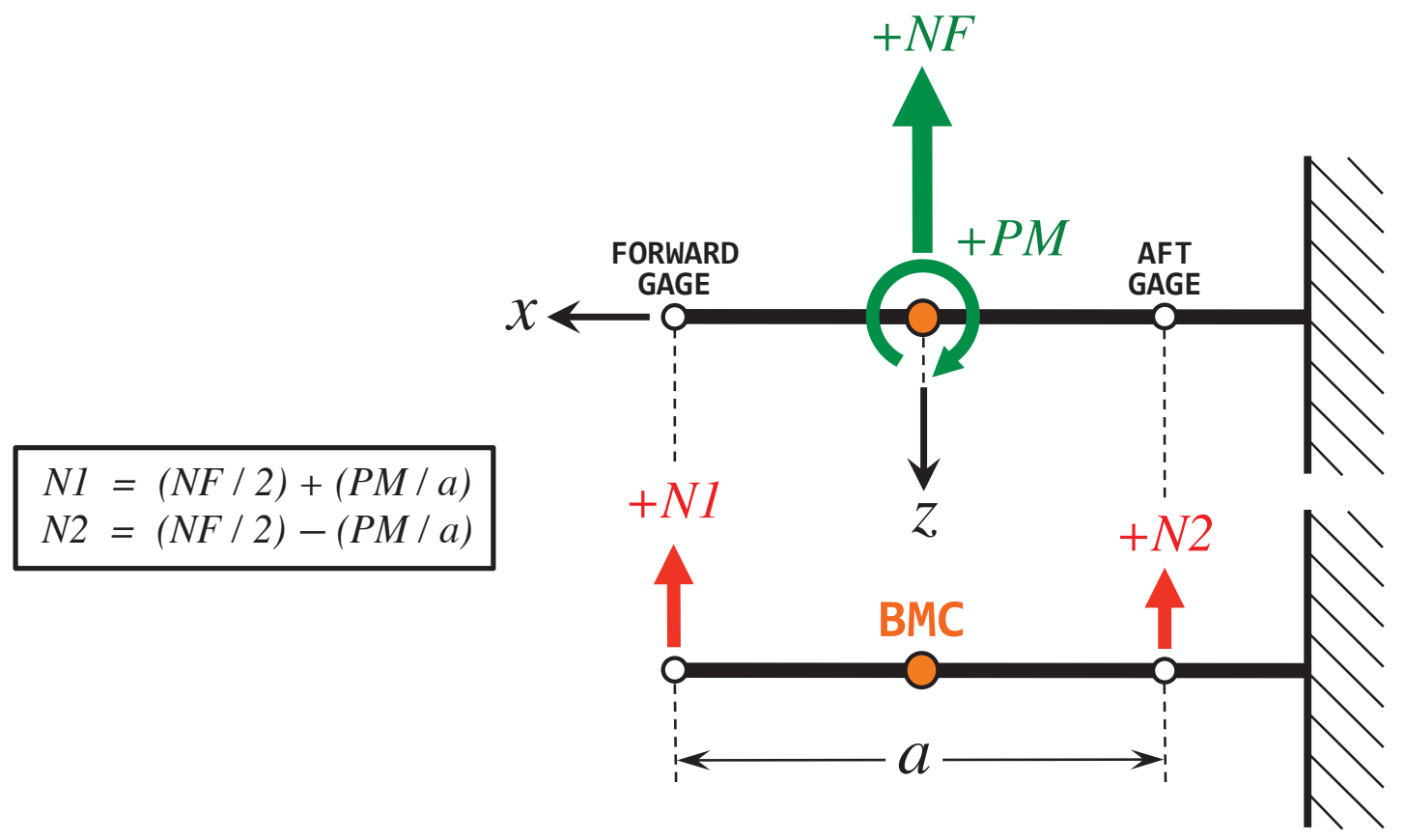

Fig. 2a Transformation of the normal force and pitching moment to "force balance" format. 


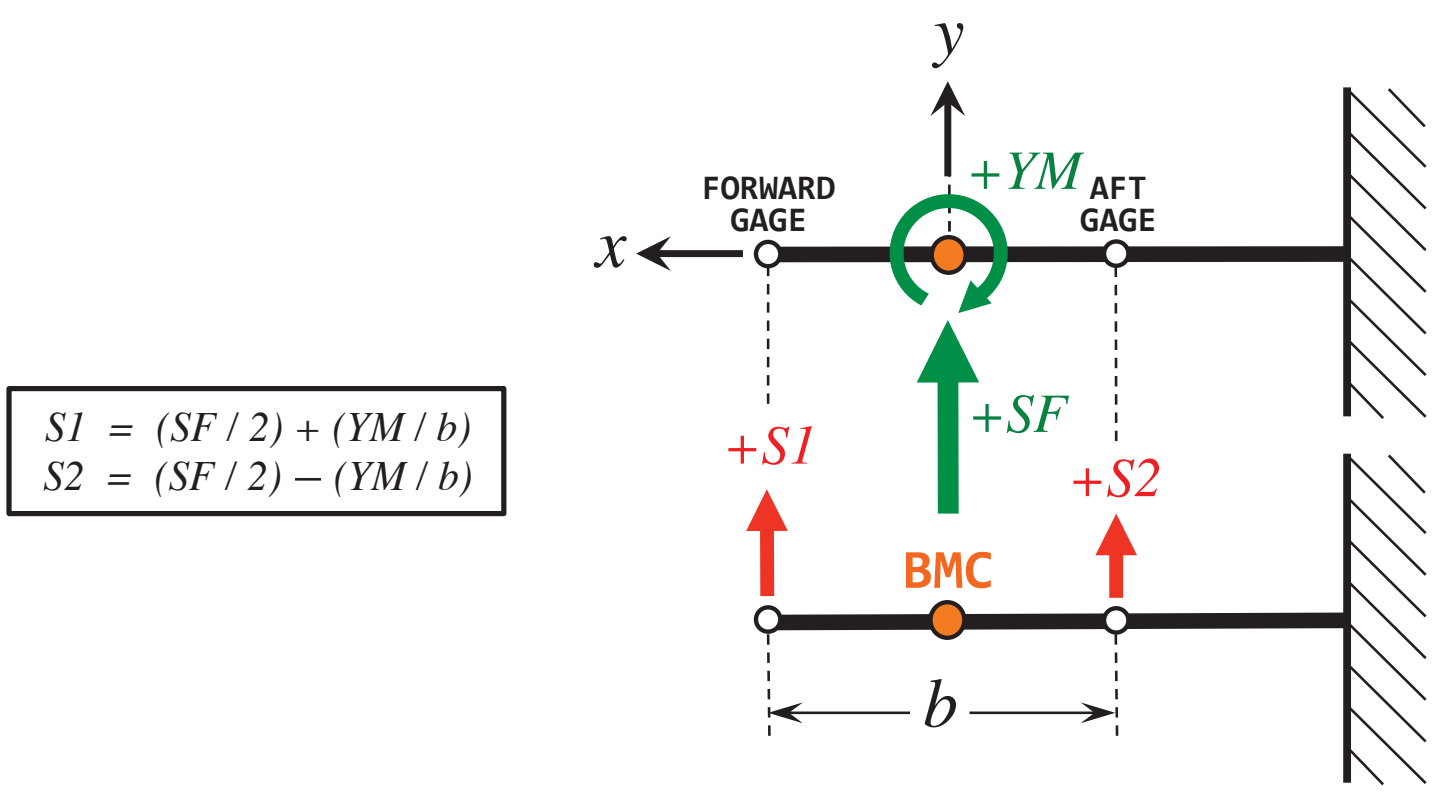

Fig. 2b Transformation of the side force and yawing moment to "force balance" format.

\begin{tabular}{|c|c|c|c|c|c|c|c|}
\hline SERIES & POINTS & N1 & N2 & S1 & S2 & RM & AF \\
\hline 1 & 17 & $\begin{array}{c} \pm N 1 \\
-100.0 \% \text { to }+100.0 \%\end{array}$ & $< \pm 2 \%$ & $< \pm 2 \%$ & $< \pm 2 \%$ & $< \pm 2 \%$ & $< \pm 2 \%$ \\
\hline 2 & 17 & $< \pm 2 \%$ & $\begin{array}{c} \pm N 2 \\
-100.0 \% \text { to }+100.0 \%\end{array}$ & $< \pm 2 \%$ & $< \pm 2 \%$ & $< \pm 2 \%$ & $< \pm 2 \%$ \\
\hline 3 & 17 & $< \pm 2 \%$ & $< \pm 2 \%$ & $\begin{array}{c} \pm \mathrm{S} 1 \\
-100.0 \% \text { to }+100.0 \%\end{array}$ & $< \pm 2 \%$ & $< \pm 2 \%$ & $< \pm 2 \%$ \\
\hline 4 & 17 & $< \pm 2 \%$ & $< \pm 2 \%$ & $< \pm 2 \%$ & $\begin{array}{c} \pm S 2 \\
-100.0 \% \text { to }+100.0 \%\end{array}$ & $< \pm 2 \%$ & $< \pm 2 \%$ \\
\hline 5 & 17 & $< \pm 2 \%$ & $< \pm 2 \%$ & $< \pm 2 \%$ & $< \pm 2 \%$ & $\begin{array}{c} \pm R M \\
-100.0 \% \text { to }+100.0 \%\end{array}$ & $< \pm 2 \%$ \\
\hline 6 & 17 & $< \pm 2 \%$ & $< \pm 2 \%$ & $< \pm 2 \%$ & $< \pm 2 \%$ & $< \pm 2 \%$ & $\begin{array}{c} \pm A F \\
-100.0 \% \text { to }+100.0 \%\end{array}$ \\
\hline 7 & 105 & $\begin{array}{c} \pm N 1 \\
-100.0 \% \text { to }+100.0 \%\end{array}$ & $\begin{array}{c} \pm N 2 \\
-100.0 \% \text { to }+100.0 \%\end{array}$ & $< \pm 2 \%$ & $< \pm 2 \%$ & $< \pm 2 \%$ & $< \pm 2 \%$ \\
\hline 8 & 105 & $< \pm 2 \%$ & $< \pm 2 \%$ & $\begin{array}{c} \pm \mathrm{S} 1 \\
-100.0 \% \text { to }+100.0 \%\end{array}$ & $\begin{array}{c} \pm S 2 \\
-100.0 \% \text { to }+100.0 \%\end{array}$ & $< \pm 2 \%$ & $< \pm 2 \%$ \\
\hline 9 & 105 & $< \pm 2 \%$ & $< \pm 2 \%$ & $< \pm 2 \%$ & $< \pm 2 \%$ & $\begin{array}{c} \pm R M \\
-100.0 \% \text { to }+100.0 \%\end{array}$ & $\begin{array}{c} \pm A F \\
-100.0 \% \text { to }+100.0 \%\end{array}$ \\
\hline 10 & 180 & $\begin{array}{c} \pm N 1 \\
-66.0 \% \text { to }+66.0 \%\end{array}$ & $\begin{array}{c} \pm N 2 \\
-66.0 \% \text { to }+66.0 \%\end{array}$ & $< \pm 2 \%$ & $< \pm 2 \%$ & $< \pm 2 \%$ & $\begin{array}{c} \pm A F \\
-66.0 \% \text { to }+66.0 \%\end{array}$ \\
\hline 11 & 180 & $< \pm 2 \%$ & $< \pm 2 \%$ & $\begin{array}{c} \pm \mathrm{S} 1 \\
-66.0 \% \text { to }+66.0 \%\end{array}$ & $\begin{array}{c} \pm S 2 \\
-66.0 \% \text { to }+66.0 \%\end{array}$ & $< \pm 2 \%$ & $\begin{array}{c} \pm A F \\
-66.0 \% \text { to }+66.0 \%\end{array}$ \\
\hline 12 & 180 & $\begin{array}{c} \pm N 1 \\
-66.0 \% \text { to }+66.0 \%\end{array}$ & $\begin{array}{c} \pm N 2 \\
-66.0 \% \text { to }+66.0 \%\end{array}$ & $< \pm 2 \%$ & $< \pm 2 \%$ & $\begin{array}{c} \pm R M \\
-66.0 \% \text { to }+66.0 \%\end{array}$ & $< \pm 2 \%$ \\
\hline 13 & 180 & $< \pm 2 \%$ & $< \pm 2 \%$ & $\begin{array}{c} \pm \mathrm{S} 1 \\
-66.0 \% \text { to }+66.0 \%\end{array}$ & $\begin{array}{c} \pm S 2 \\
-66.0 \% \text { to }+66.0 \%\end{array}$ & $\begin{array}{c} \pm \mathrm{RM} \\
-66.0 \% \text { to }+66.0 \%\end{array}$ & $< \pm 2 \%$ \\
\hline 14 & 513 & $\begin{array}{c} \pm N 1 \\
-66.0 \% \text { to }+66.0 \%\end{array}$ & $\begin{array}{c} \pm N 2 \\
-66.0 \% \text { to }+66.0 \%\end{array}$ & $\begin{array}{c} \pm \mathrm{S} 1 \\
-66.0 \% \text { to }+66.0 \%\end{array}$ & $\begin{array}{c} \pm S 2 \\
-66.0 \% \text { to }+66.0 \%\end{array}$ & $< \pm 2 \%$ & $< \pm 2 \%$ \\
\hline 15 & 216 & $\begin{array}{c} \pm N 1 \\
-33.0 \% \text { to }+33.0 \%\end{array}$ & $\begin{array}{c} \pm \mathrm{N} 2 \\
-33.0 \% \text { to }+33.0 \%\end{array}$ & $\begin{array}{c} \pm \mathrm{S} 1 \\
-33.0 \% \text { to }+33.0 \%\end{array}$ & $\begin{array}{c} \pm S 2 \\
-33.0 \% \text { to }+33.0 \%\end{array}$ & $< \pm 2 \%$ & $\begin{array}{c} \pm \mathrm{AF} \\
-33.0 \% \text { to }+33.0 \%\end{array}$ \\
\hline 16 & 216 & $\begin{array}{c} \pm N 1 \\
-33.0 \% \text { to }+33.0 \%\end{array}$ & $\begin{array}{c} \pm N 2 \\
-33.0 \% \text { to }+33.0 \%\end{array}$ & $\begin{array}{c} \pm \mathrm{S} 1 \\
-33.0 \% \text { to }+33.0 \%\end{array}$ & $\begin{array}{c} \pm S 2 \\
-33.0 \% \text { to }+33.0 \%\end{array}$ & $\begin{array}{c} \pm \mathrm{RM} \\
-33.0 \% \text { to }+33.0 \%\end{array}$ & $< \pm 2 \%$ \\
\hline
\end{tabular}

Fig. 3 Description of the 2082-point load schedule for a force balance (red color $=$ single-component load). 
N1, \% OF CAPACITY (1000.0 [lbs])

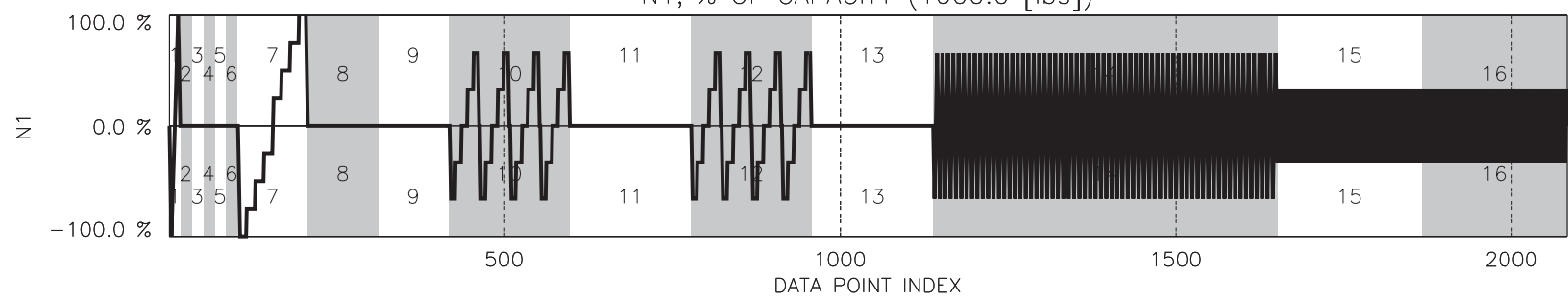

N2, \% OF CAPACITY (1000.0 [lbs])

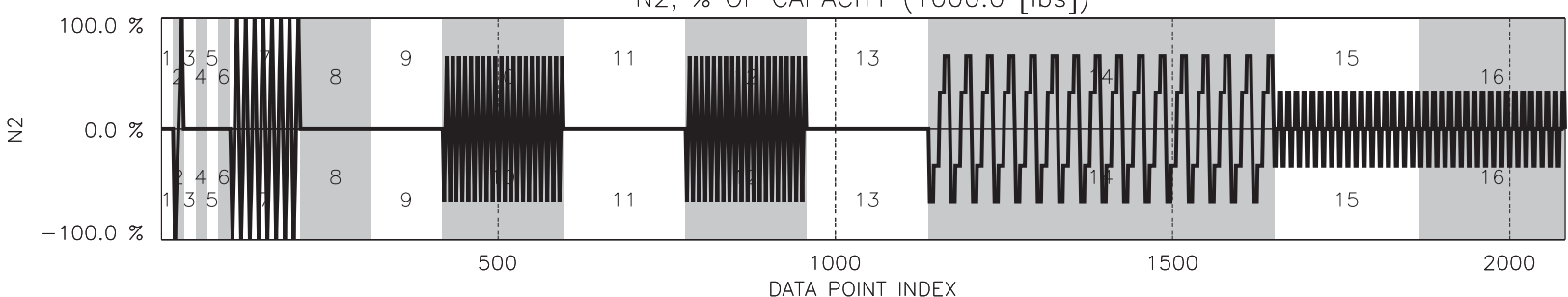

S1, \% OF CAPACITY (800.0 [lbs])

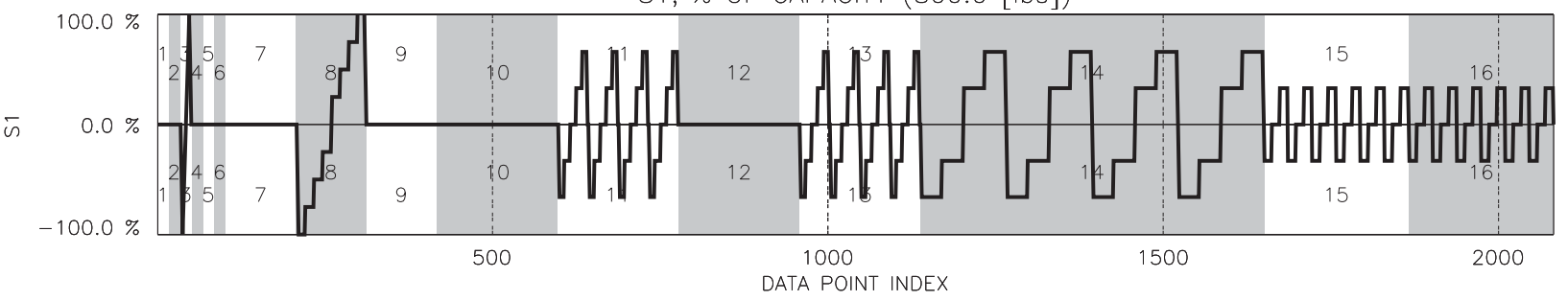

S2, \% OF CAPACITY (800.0 [lbs])
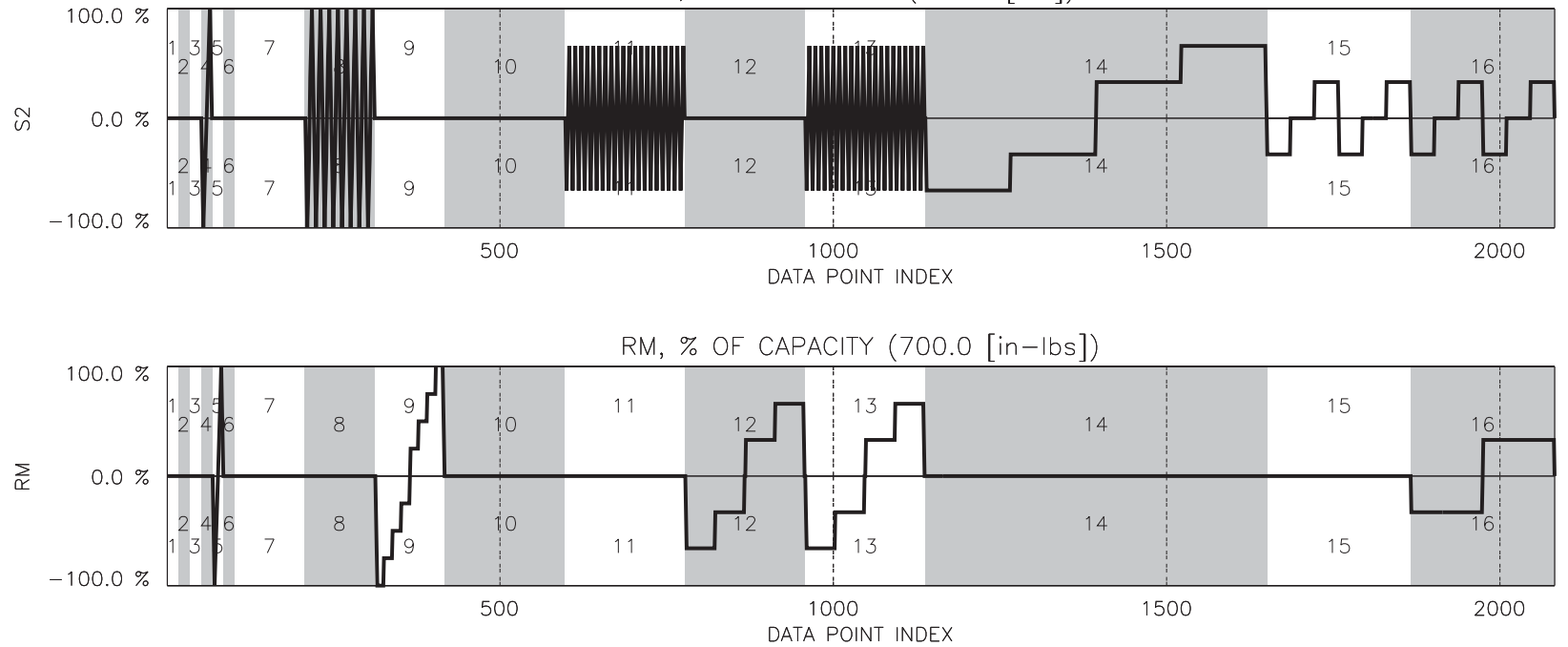

AF, \% OF CAPACITY (2000.0 [lbs])

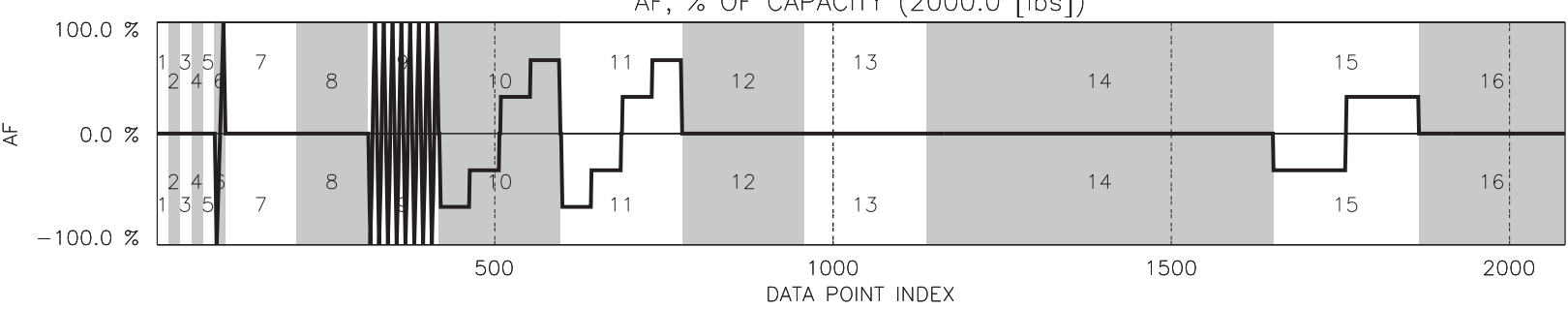

Fig. 4 Loads of the "hypothetical" 2082-point load schedule for the MK26A balance example. 

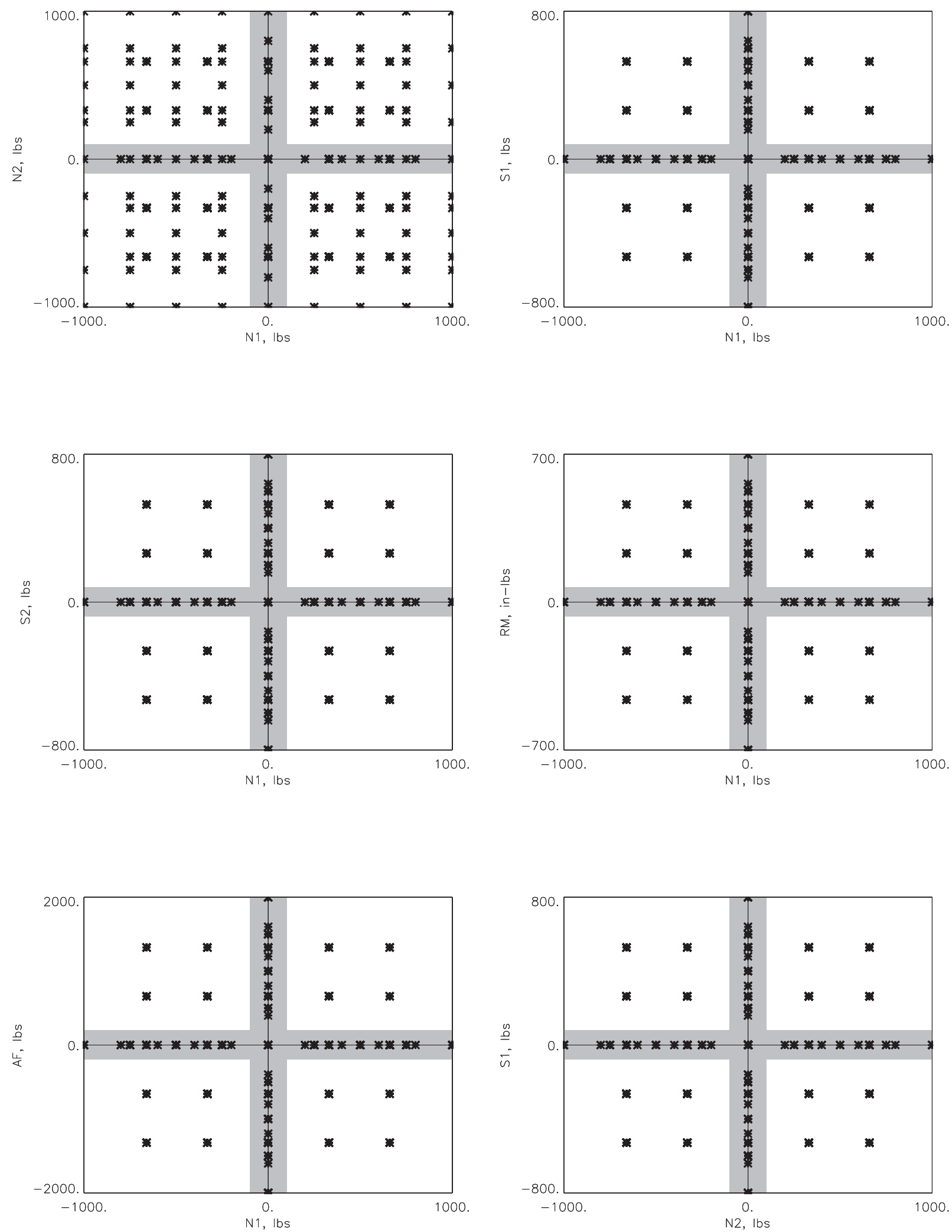

Fig. 5a Combined load plots of the 2082-point load schedule for the MK26A balance (plots 1 to 6). 

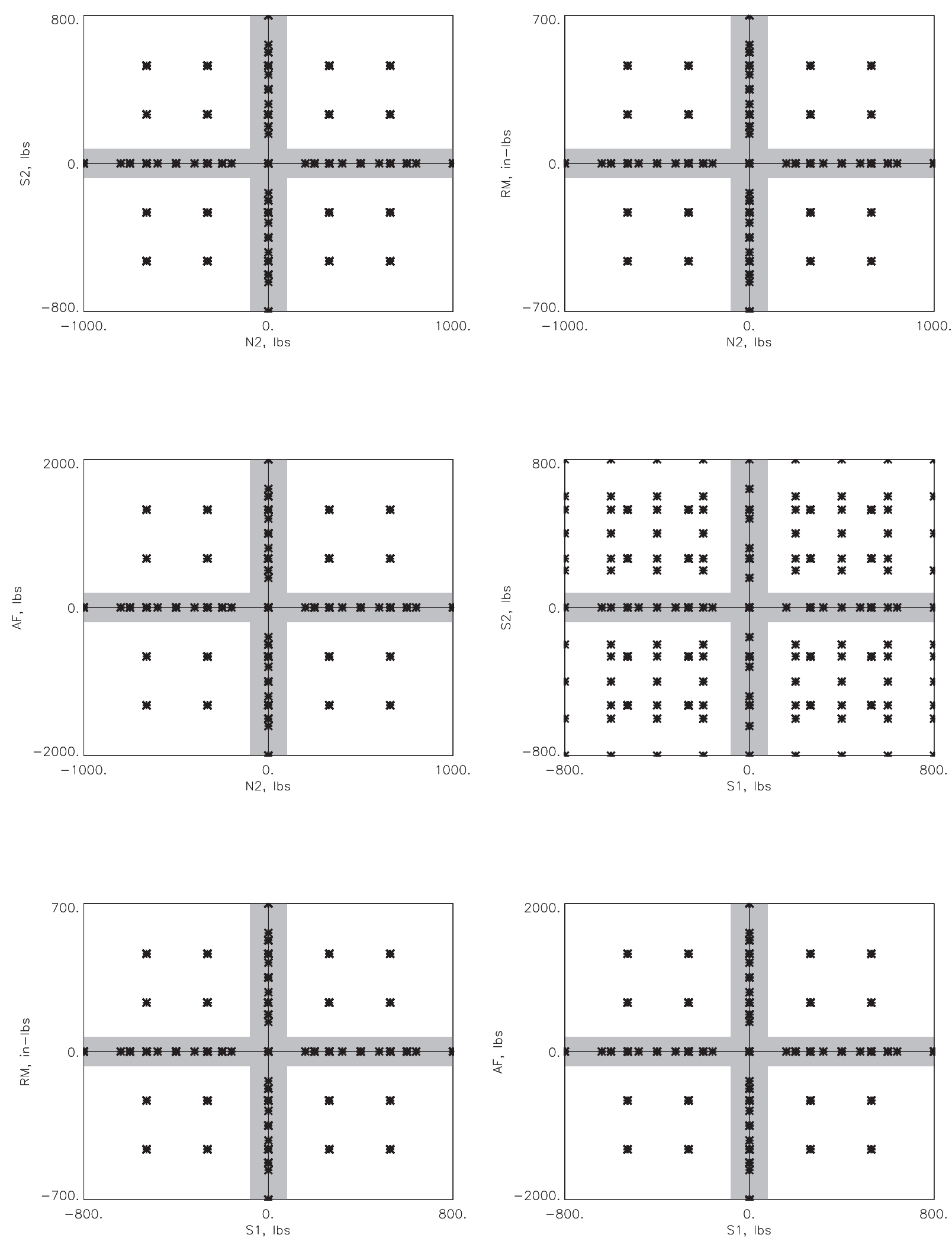

Fig. 5b Combined load plots of the 2082-point load schedule for the MK26A balance (plots 7 to 12). 

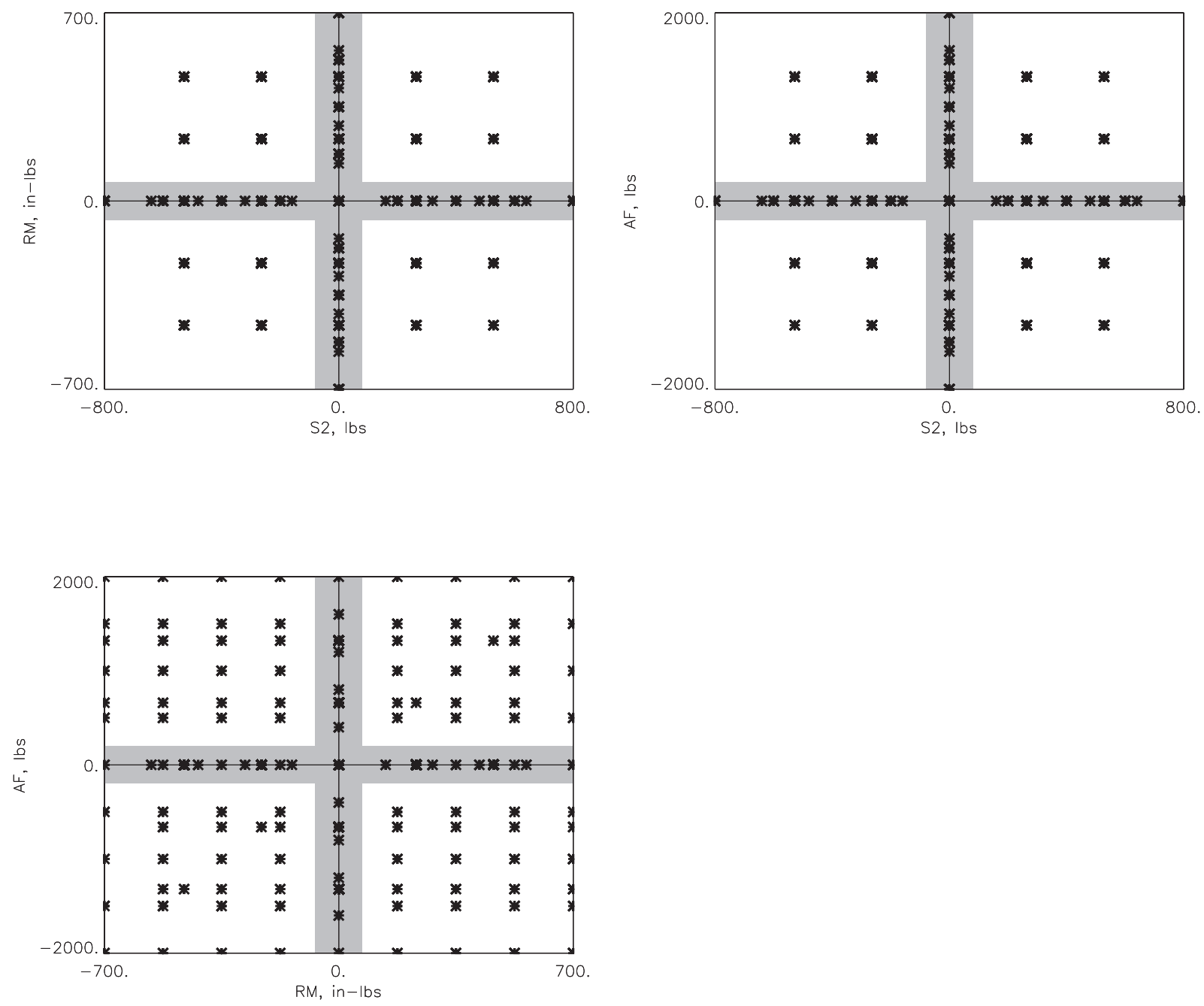

Fig. 5c Combined load plots of the 2082-point load schedule for the MK26A balance (plots 13 to 15). 
N1, \% OF CAPACITY (5000.0 [lbs])

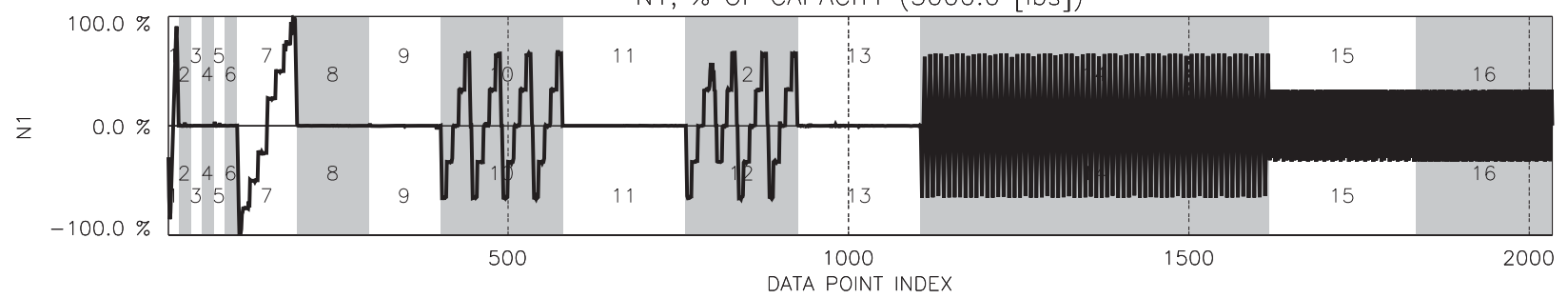

N2, \% OF CAPACITY (5000.0 [lbs])

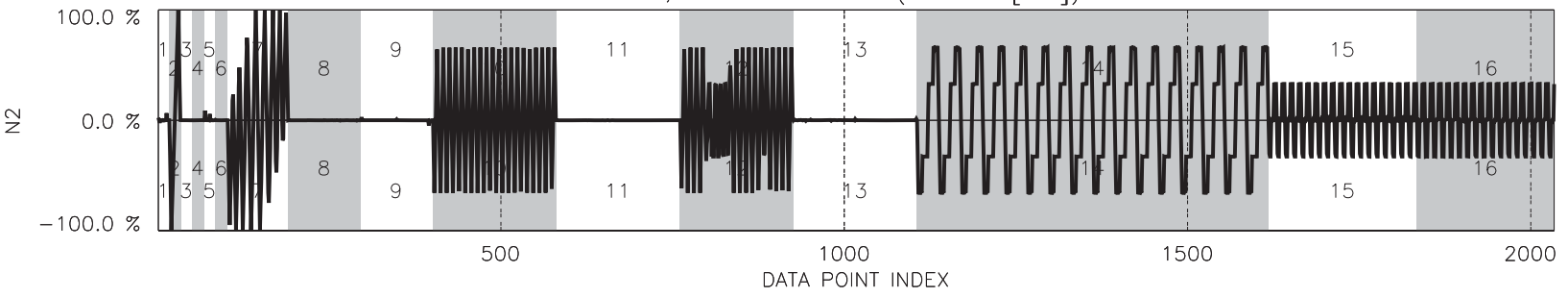

S1, \% OF CAPACITY (2500.0 [lbs])

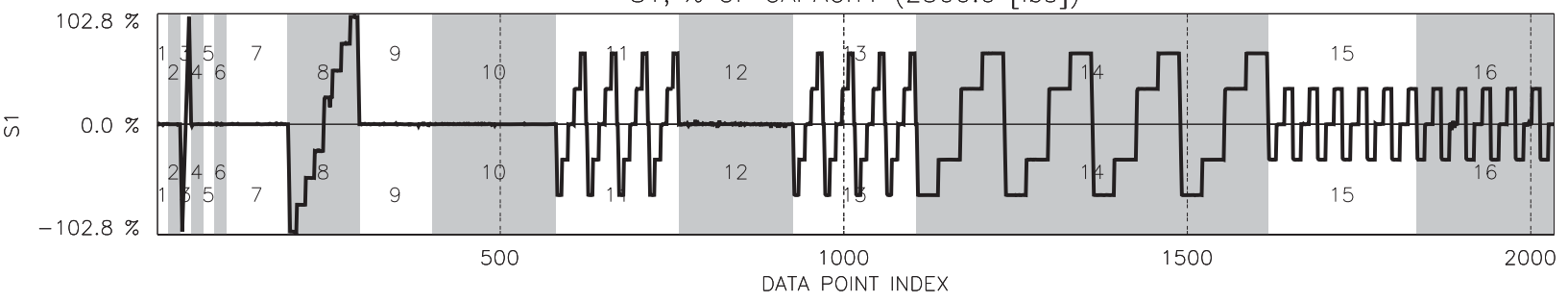

S2, \% OF CAPACITY (2500.0 [lbs])

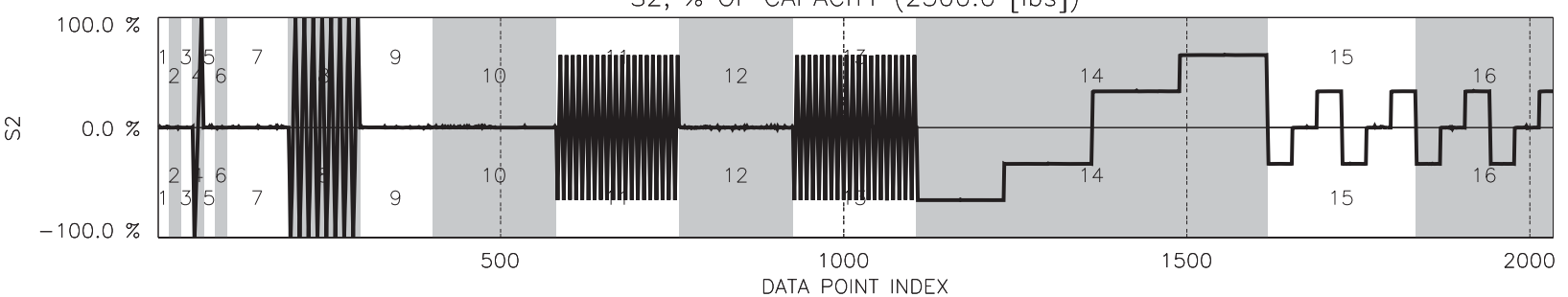

RM, \% OF CAPACITY (18000.0 [in-lbs])
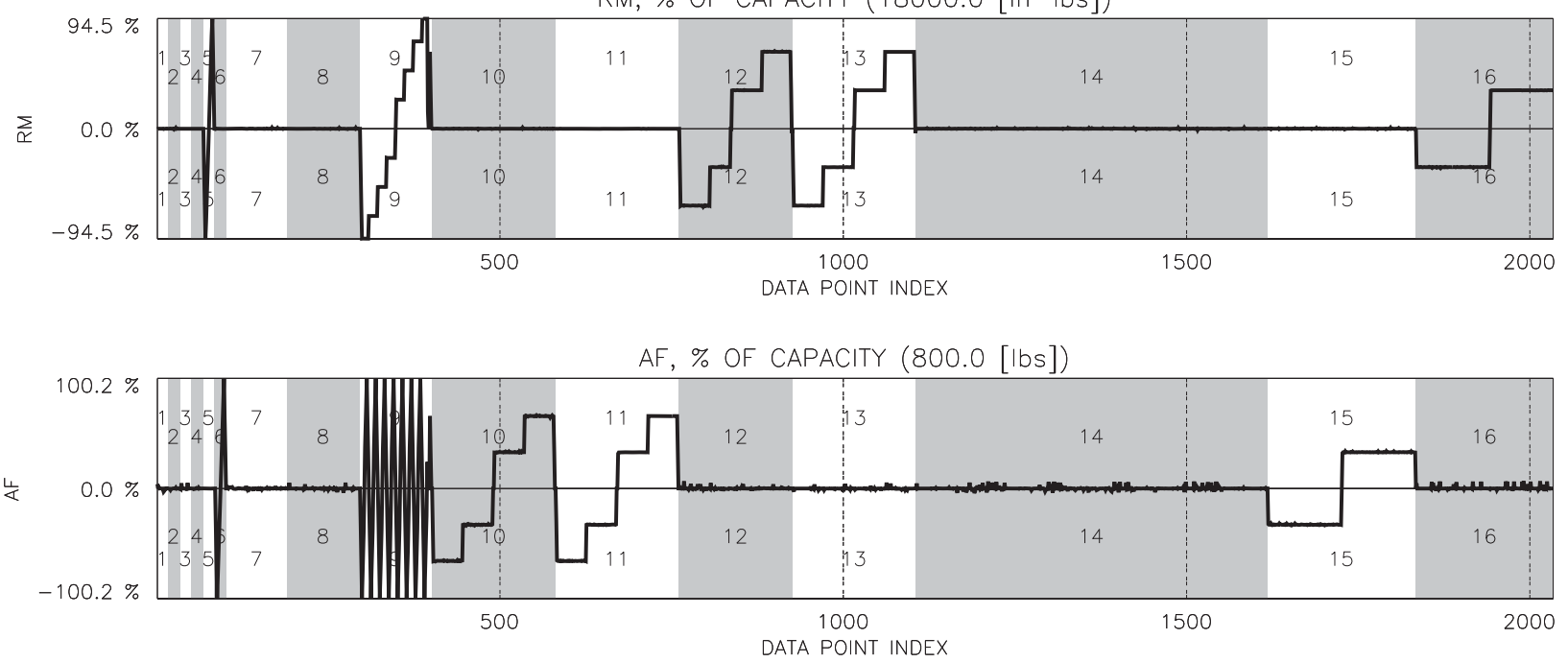

Fig. 6 Applied machine calibration loads of the 2034-point load schedule for the MC100A balance. 
$\triangle N 1, \%$ OF CAPACITY; STANDARD DEVIATION $=3.3659$ [Ibs] OR $0.0673 \%$

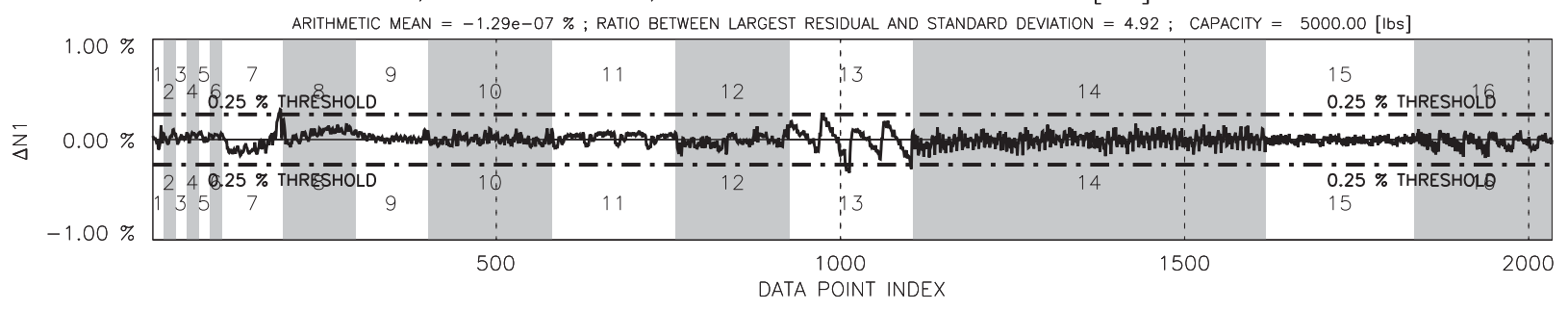

$\triangle \mathrm{N} 2, \%$ OF CAPACITY ; STANDARD DEVIATION $=3.4926$ [Ibs] OR $0.0699 \%$

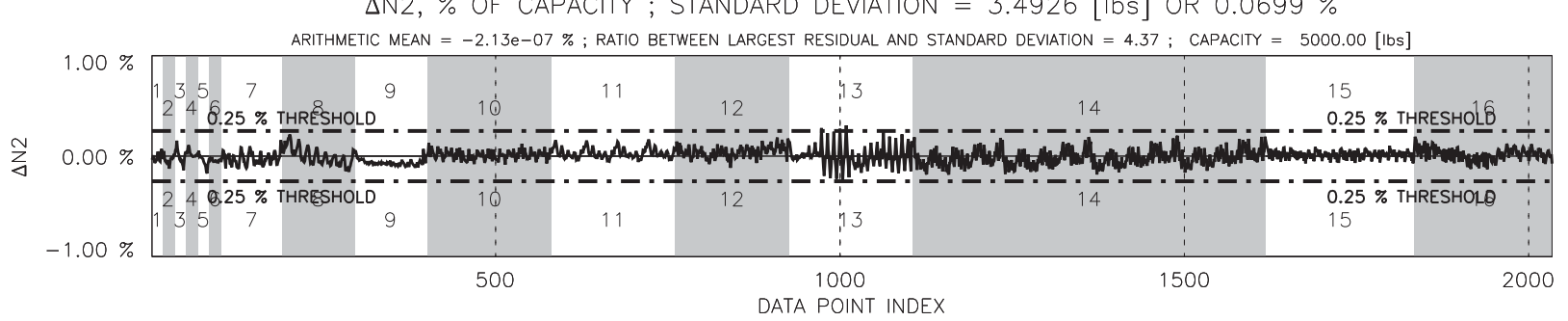

$\triangle \mathrm{S} 1, \%$ OF CAPACITY ; STANDARD DEVIATION $=4.2326$ [Ibs] OR $0.1693 \%$

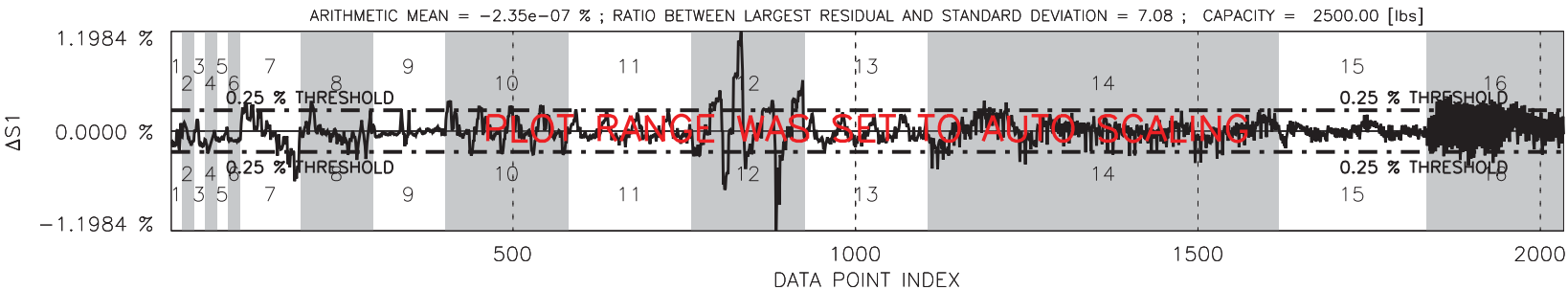

$\triangle S 2, \%$ OF CAPACITY ; STANDARD DEVIATION $=3.9328$ [Ibs] OR $0.1573 \%$
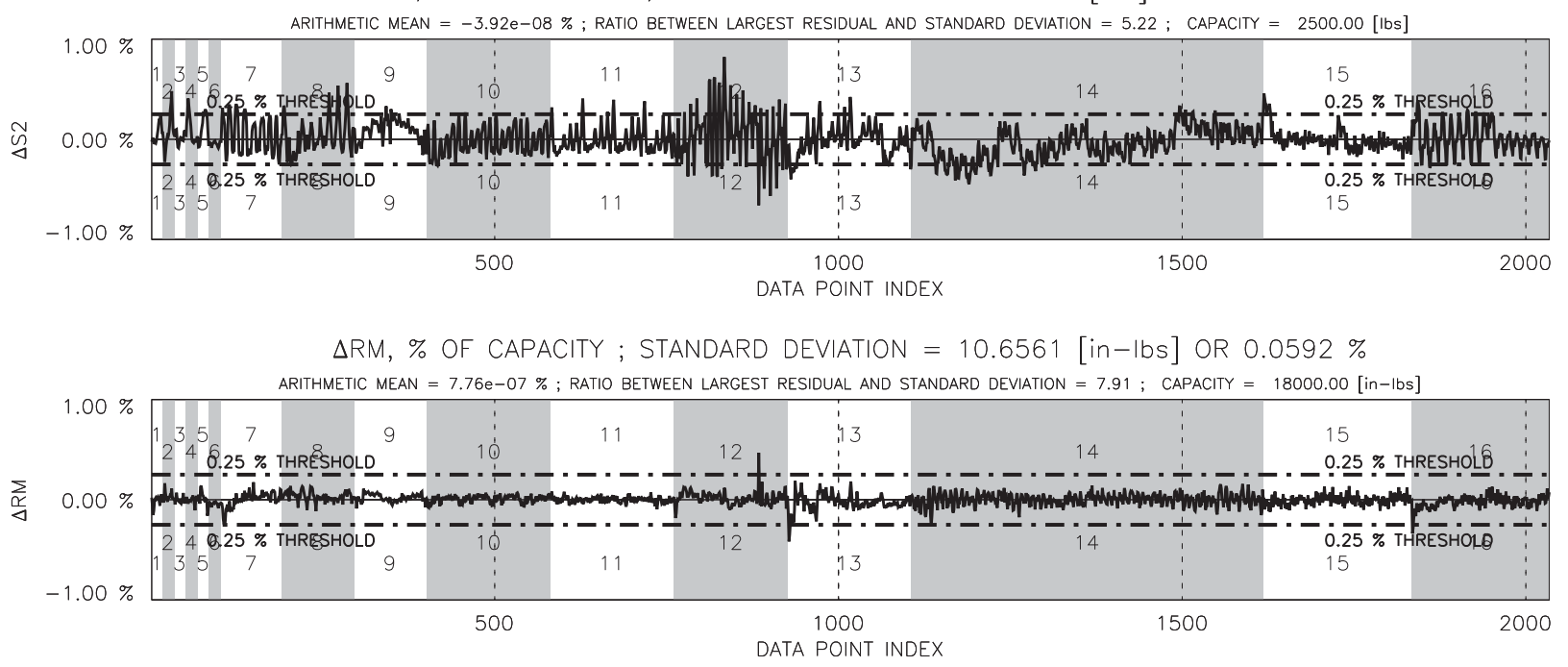

$\triangle \mathrm{AF}, \%$ OF CAPACITY ; STANDARD DEVIATION $=1.1395$ [ lbs] OR $0.1424 \%$

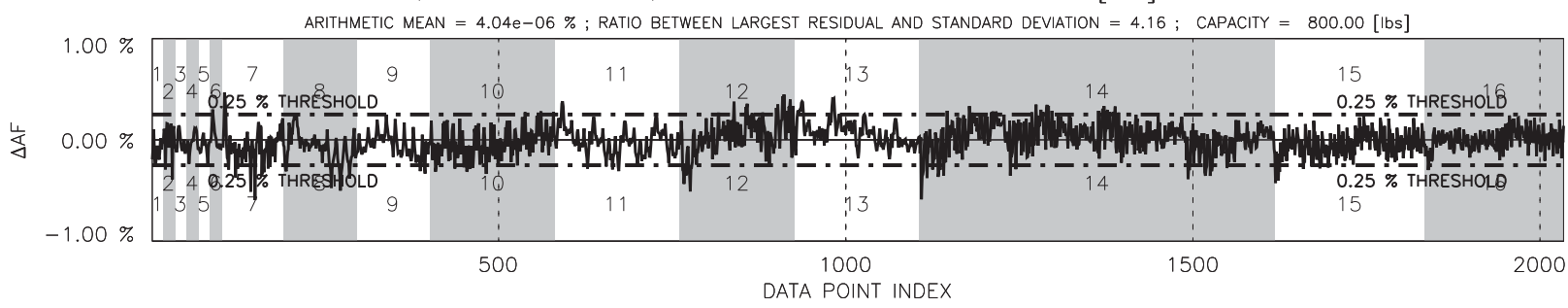

Fig. 7a Preliminary calibration load residuals for the MC100A balance plotted versus the load series.

American Institute of Aeronautics and Astronautics 
$\triangle N 1, \%$ OF CAPACITY ; STANDARD DEVIATION = 3.3659 [ Ibs] OR $0.0673 \%$

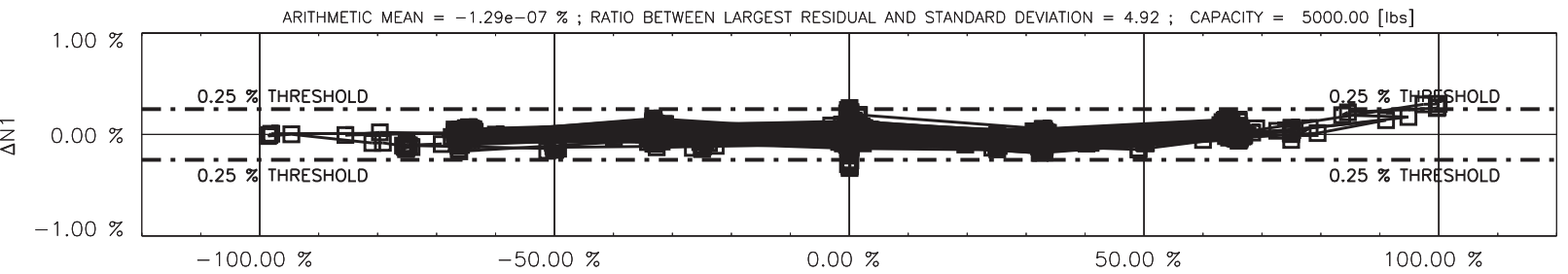

N1 (LOAD, \% OF CAPACITY)

$\triangle \mathrm{N} 2, \%$ OF CAPACITY ; STANDARD DEVIATION $=3.4926$ [lbs] OR $0.0699 \%$

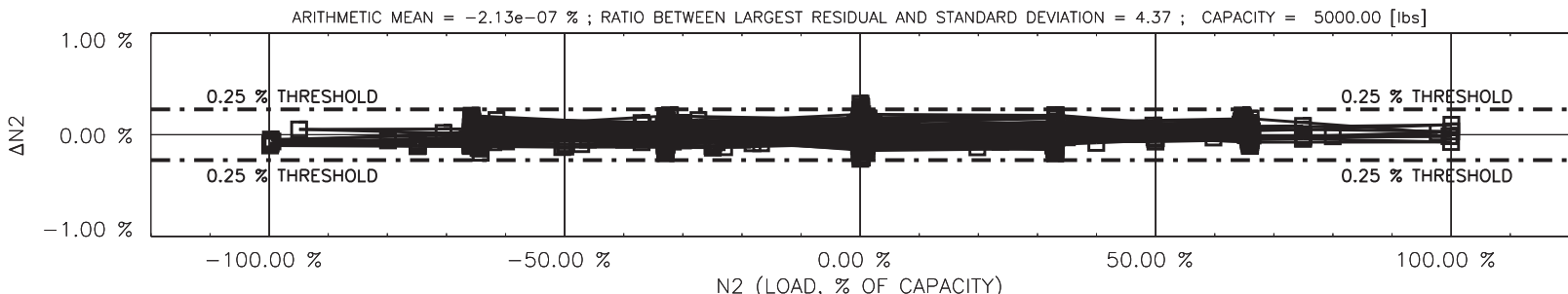

N2 (LOAD, \% OF CAPACITY)

$\triangle \mathrm{S} 1, \%$ OF CAPACITY ; STANDARD DEVIATION $=4.2326$ [lbs] OR $0.1693 \%$

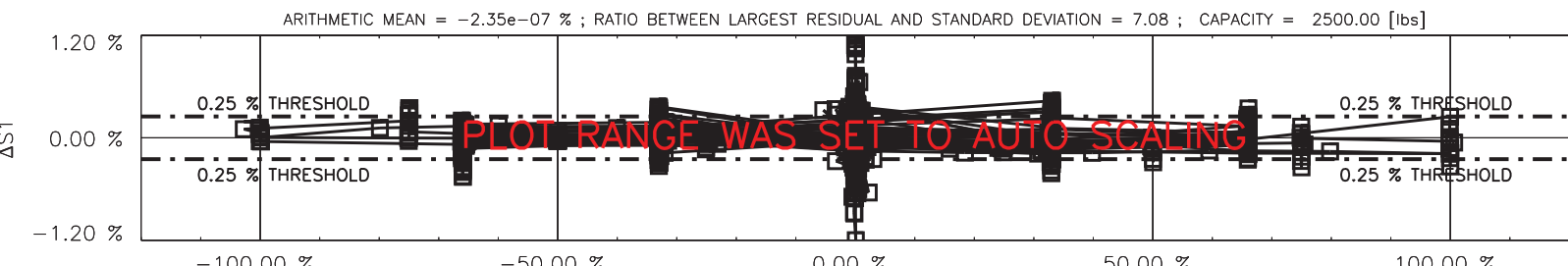
$-100.00 \%$
$-50.00 \%$
S1 (LOAD, \% OF CAPACITY)

$\triangle \mathrm{S} 2, \%$ OF CAPACITY ; STANDARD DEVIATION $=3.9328$ [Ibs] OR $0.1573 \%$

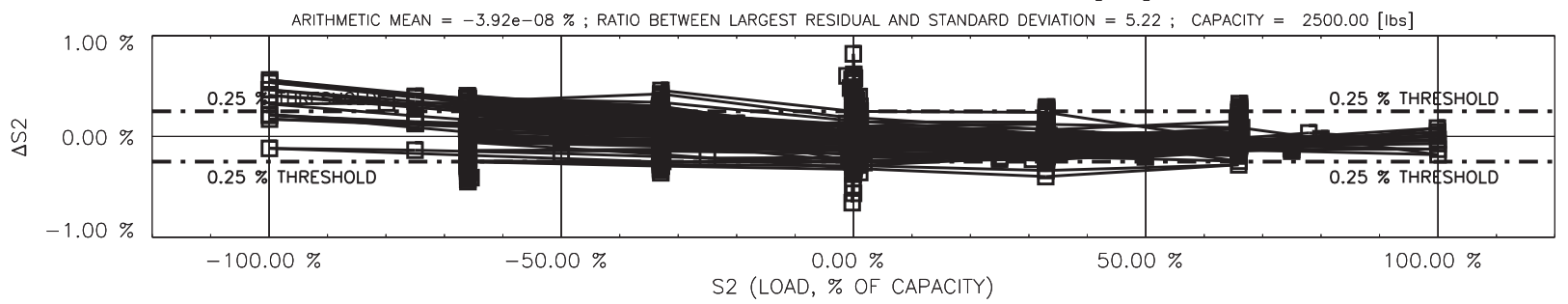

$\triangle R M, \%$ OF CAPACITY ; STANDARD DEVIATION $=10.6561$ [in-lbs] OR $0.0592 \%$

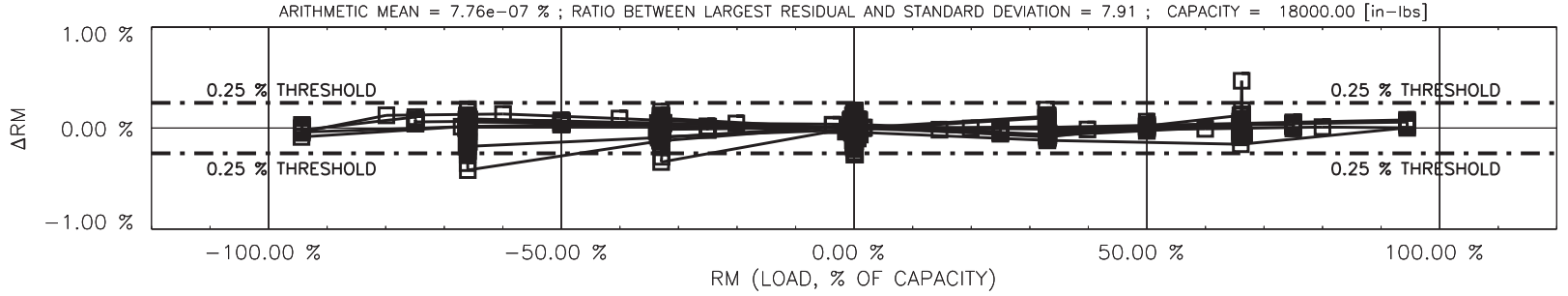

$\triangle \mathrm{AF}, \%$ OF CAPACITY; STANDARD DEVIATION $=1.1395$ [lbs] OR $0.1424 \%$

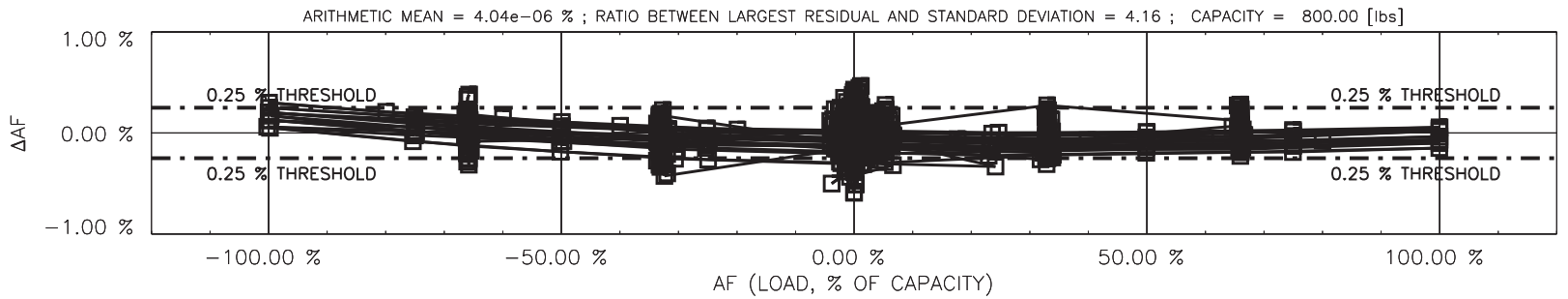

Fig. 7b Preliminary calibration load residuals for the MC100A balance plotted versus the applied load.

American Institute of Aeronautics and Astronautics 